\title{
DESAFIOS DAS ORGANIZAÇÕES CONTÁBEIS ACERCA DO eSOCIAL APÓS SUA IMPLEMENTAÇÃO
}

\author{
CHALLENGES OF ACCOUNTING ORGANIZATIONS ABOUT ESOCIAL AFTER \\ IMPLEMENTATION
}

\author{
Felipe Opuszka Conceição ${ }^{1}$ \\ Universidade do Vale do Itajaí (UNIVALI) \\ felipeopuszka@hotmail.com
}

\author{
Lucas Ferreira Lima \\ Universidade do Vale do Itajaí (UNIVALI) \\ lucas_ferreira_1@hotmail.com
}

\section{Zilton Bartolomeu Martins}

Universidade do Vale do Itajaí (UNIVALI)

ziltonmartins@univali.br

\section{RESUMO}

Este artigo teve como objetivo analisar os desafios de organizações contábeis acerca do eSocial após sua implementação. Foi utilizado o método de pesquisa quantitativa, descritiva e de levantamento. $\mathrm{O}$ instrumento de coleta de dados foi um questionário validado e utilizado por Muller, Godoy Filho e Martins (2019), com 20 (vinte) questões fechadas. A população deste estudo foi de 2840 escritórios de Contabilidade da Grande Florianópolis/SC, obtendo-se uma amostra de 61 respondentes, que representa $2,15 \%$ da população. Os dados foram tabulados por meio do Google Formulários ${ }^{\circledR}$ e a técnica de análise de dados utilizada foi a estatística descritiva, segundo a distribuição de frequência relativa. Como principais resultados, foi possível observar que as organizações contábeis não estão preparadas em relação ao eSocial. Destaca-se também que apesar de grande maioria dos respondentes ter conhecimento do eSocial, mostram-se sem capacitação adequada. Por fim, constatou-se que apesar da baixa carga horária de participação em cursos, tem-se um alto conhecimento sobre o grau das penalidades aplicadas pelo eSocial.

Palavras-Chave: eSocial. Implementação. Organizações Contábeis.

\footnotetext{
${ }^{1}$ Rua João Coan, 400 - Bairro Universitário - Biguaçu/SC - CEP 88.161-064

*Artigo apresentado no $17^{\circ}$ Encontro Catarinense de Estudantes de Ciências Contábeis (2019).
} 


\section{ABSTRACT}

This article aims to analyze the challenges of accounting organizations about eSocial after its implementation. The quantitative, descriptive and survey method was used. The data collection instrument was a validated questionnaire used by Muller, Godoy Filho and Martins (2019), with 20 (twenty) closed questions. The population of this study was 2840 Accounting Offices of Grande Florianopolis/SC, obtaining a sample of 61 respondents, representing $2.15 \%$ of the population. Data were tabulated using Google Forms ${ }^{\circledR}$ and the data analysis technique used was descriptive statistics according to the relative frequency distribution. As main results, it was observed that accounting organizations are not prepared in relation to eSocial. It is also noteworthy that although most respondents have knowledge of eSocial, they are without adequate training. Finally, it was found that despite the low hours of participation in courses, there is a high knowledge about the degree of penalties applied by eSocial.

Keywords: eSocial. Implementation. Accounting Organizations.

\section{INTRODUÇÃO}

A contabilidade existe desde a época primitiva e sempre foi considerada muito importante no controle do patrimônio. Tem evoluído muito desde sua existência, deixando de realizar vários processos manuais, para fazê-los de forma automática e informatizada (BARP; VIEIRA; MARTINS, 2014). Isto foi possível devido ao avanço da tecnologia, possibilitando a integração de informações entre organizações, empresários e contadores, auxiliando nos processos cotidianos das empresas (CAON; NASCIMENTO, 2017).

Com este avanço na tecnologia, a contabilidade passou a efetuar escriturações digitais e uma das peças fundamentais para isto foi o surgimento do SPED (Sistema Público de Escrituração Digital). O SPED, de modo geral, consiste na transmissão das obrigações acessórias dos contribuintes para as administrações tributárias e órgãos fiscalizadores, tendo sua assinatura por meio de certificado digital, garantido assim, a sua validade jurídica. Dentre estas obrigações, consta o eSocial (BARP; VIEIRA; MARTINS, 2014).

O eSocial é uma das obrigações acessórias do SPED e abrange a folha de pagamento, as obrigações trabalhistas, previdenciárias e fiscais, atendendo informações para órgãos como o Ministério do trabalho e Emprego (MTE), Instituto Nacional do Seguro Social (INSS), Caixa Econômica Federal (CEF), Fundo de Garantia do Tempo de Serviço (FGTS) e Justiça do trabalho, trazendo mudanças significativas nos processos contábeis e administrativos, e em sistemas de apoio a gestão empresarial (COSTA et al., 2018).

O sistema está padronizado para o envio das informações, instituindo uma série de medidas que deveriam ter se tornado obrigatórias em 2014, porém nenhuma entrou em vigor, passando a obrigatoriedade para as empresas a partir de janeiro de 2018 (COSTA; OLIVEIRA; ALVES, 2016; PORTAL ESOCIAL, 2018).

Diante do exposto, surge a pergunta de pesquisa: Quais os desafios das organizações contábeis acerca do eSocial após sua implementação? Para responder este questionamento, apresenta-se o seguinte objetivo geral: analisar os desafios de organizações contábeis acerca do eSocial após sua implementação.

Como justificativa teórica, Oliveira, Santana e Martins (2017) analisaram as perspectivas dos contadores em relação à implantação do eSocial e sugerem que seja feita nova pesquisa no intuito de descobrir se as perspectivas dos profissionais, de fato, se concretizaram, após a implantação do eSocial. Já Vellucci et al. (2018) verificaram como está a adaptabilidade das organizações na implantação do eSocial, bem como, práticas que estão em desacordo com a legislação trabalhista e que podem se apresentar como fatores críticos da implantação deste 
projeto e propõem uma nova pesquisa com número maior de respondentes do instrumento de levantamento da adaptabilidade ao eSocial pelas organizações. Por fim, Muller, Godoy Filho e Martins (2019) analisaram as dificuldades da implantação do eSocial nas organizações contábeis e recomendam trabalhar com uma amostra de público mais específico do setor de Recursos Humanos e Departamento de Pessoal.

A título de justificativa empírica, o estudo pretende esclarecer o relacionamento das normas do eSocial com os profissionais de organizações contábeis após a sua implantação, relatando suas responsabilidades com o envio dos dados. Como é um assunto recente, esta pesquisa pode auxiliar as organizações a verificar os pontos em que se tem maior dificuldade para efetuar uma ação de melhoria no cumprimento desta obrigação acessória.

\section{FUNDAMENTAÇÃO TEÓRICA}

A fundamentação teórica desta pesquisa está dividida em: Sistema Público de Escrituração Digital (SPED), eSocial e estudos anteriores sobre o tema.

\subsection{SISTEMA PÚBLICO DE ESCRITURAÇÃO DIGITAL (SPED)}

Devido ao avanço tecnológico, a contabilidade entrou na era digital, possibilitando a integração e padronização de informações contábeis, gerando informações de maior qualidade e permitindo uma melhor fiscalização pela administração tributária. A partir desta evolução, foi criado o Sistema Público de Escrituração DIGITAL (SPED) (ORIGUELA, 2017).

O SPED foi instituído pelo Decreto n ${ }^{\circ} 6.022$ de 22 de janeiro de 2007 e faz parte do Programa de Aceleração do Crescimento do Governo Federal. Consiste na transmissão de obrigações acessórias pelos contribuintes às administrações tributárias e aos órgãos fiscalizadores, utilizando certificação digital para assinatura dos documentos eletrônicos, garantindo sua validade jurídica na forma digital. Sendo assim, este pode ser considerado um avanço na informatização de relação entre a administração tributária e os contribuintes (GONÇALVES et al., 2016).

Esta ferramenta do Governo Federal também pode ser definida como a inovação da relação entre o fisco e os contribuintes, devido à unificação (das atividades) de envio de informações para as autarquias, sendo observada como uma forma de impedimento à sonegação de fiscal e ilegalidades na arrecadação tributária (OLIVEIRA; SANTANA; MARTINS, 2017). Neste sentido, Azevedo e Mariano (2011) apontam que o SPED efetua a realização de cruzamentos de informações, desta forma, mostrando inconsistências das informações, o que facilita identificar ilícitos tributários, diminuindo a quantidade de declarações entregues pelos contribuintes, uma vez que busca unificá-las.

De acordo com Origuela (2017) este sistema está composto por vários projetos, sendo eles: a Escrituração Contábil Digital (ECD), Escrituração Fiscal Digital (EFD), Nota Fiscal Eletrônica (NF-e), Conhecimento de Transporte eletrônico (CT-e); Nota Fiscal de Serviços Eletrônica (NFS-e), Escrituração Fiscal Digital das Contribuições Incidentes sobre a Receita (EFD-Contribuições), o eSocial, que é a Folha de Pagamento Digital, o e-LALUR (Livro de apuração do Lucro Real); Escrituração Fiscal Digital das Retenções e Informações da Contribuição Previdenciária Substituída (EFD-Reinf), Escrituração Fiscal Digital do Imposto sobre Circulação de Mercadorias e Serviços (ICMS) e Imposto sobre Produtos Industrializados (IPI) (EFD-ICMS/IPI).

Ressalta-que a ECD tem por objetivo a troca da escrituração em papel de livros Diários, Razão, Balancetes diários e Balanços por arquivos digitais, trazendo as informações de forma mais detalhada. A EFD-ICMS/IPI se constitui na substituição da escrituração do Livro de Registro de Apuração do ICMS e IPI, do Livro Registro de Entradas, do Livro Registro de 
Saídas e do Livro Registro de Inventário, onde são assinados digitalmente e enviado via internet para o ambiente SPED. Já a EFD-Contribuições se trata de um registro digital utilizado para levantamento do Programa de Integração Social (PIS) e da Contribuição para o Financiamento da Seguridade Social (COFINS), além das informações da contribuição previdenciária incidente sobre a receita, no regime de apuração cumulativo ou não-cumulativo (AZEVEDO; MARIANO, 2011).

Na mesma concepção, Duarte (2011) observa que a finalidade do e-LALUR é detalhar todas as informações que influenciarem de forma direta e indireta as operações, como algumas composições da base de cálculo e o valor devido dos tributos. Como visto, o SPED trouxe ao Contador facilidade de informatização, com o objetivo de integrar fisco e contribuinte, além de melhorar as atividades contábeis, trazendo agilidade nas informações, reduzindo fraudes e assessorando na correção dos dados divergentes (CAON; NASCIMENTO, 2017).

\section{2 eSOCIAL}

O Sistema de Escrituração Digital das Obrigações Fiscais, Previdenciárias e Trabalhistas (eSocial), é um projeto do Governo Federal que foi instituído pelo Decreto 8.373 de 11 de dezembro de 2014, como um instrumento para unificação das informações fiscais, previdenciárias e trabalhistas com a finalidade de padronizar seu armazenamento, validação, distribuição e transmissão em todo território nacional (GONÇALVES et al., 2016).

Inicialmente, o eSocial teve várias denominações, como por exemplo, SPED FPD (Folha de Pagamento) e Escrituração Fiscal Digital Social (EFD-Social), mas começou a se tornar realidade como o módulo do empregado doméstico e também com a criação do Portal eSocial, que consiste em um ambiente online, no qual o empregador tem acesso ao envio de informações e também para sanar possíveis dúvidas, e uma vez implantado, o mesmo atinge todos os empregadores e empregados (FILIPIN et al., 2016).

Este projeto consiste na escrituração digital da folha de pagamento e das obrigações trabalhistas, possui uma alta complexidade e foi planejado por vários órgãos e instituições, entre eles, a Receita Federal do Brasil (RFB), o Ministério do Trabalho e Previdência Social (MTPS), o Instituto Nacional do Seguro Social (INSS) e a Caixa Econômica Federal (CEF) (OLIVEIRA; SANTANA; MARTINS, 2017). O eSocial abrange eventos trabalhistas, como a admissão de funcionários, exames ocupacionais, movimentação de férias, $13^{\circ}$ salário, entre outras informações trabalhistas. Esta inovação tende a contribuir positivamente na prestação de informações, visto que estão unificadas em um banco de dados universal, facilitando o trabalho entre todas as partes envolvidas e evitando alterações e registros retroativos (DUTRA; GONÇALVES; MARTINS, 2019).

Desta forma, Costa, Oliveira e Alves (2016) sustentam que a transmissão dos arquivos referente aos eventos trabalhistas é feita assim que eles acontecerem, obedecendo aos prazos específicos e conforme a legislação, sendo que para cada evento há um layout específico em um único arquivo. Já os dados referentes a folha de pagamento e demais informações (previdenciárias, trabalhistas e tributárias), podem ser enviadas em vários arquivos, dependendo do conteúdo a ser transmitido. Este envio é feito em duas etapas: primeiramente é transmitido um arquivo de abertura e depois um arquivo de encerramento para fiscalização.

Neste contexto, deve-se observar os prazos para envio de informações de alguns eventos. No caso de registro de admissão, devem ser enviados até o fim do dia anterior ao início da prestação de serviço. Para desligamentos, devem ser enviados até o primeiro dia útil seguinte da data da demissão, sendo nos casos de aviso prévio trabalhado ou no término de contrato por prazo determinado. Para demais casos, deve-se enviar em até 10 dias úteis do desligamento. Já a comunicação de acidente de trabalho deve ser enviada até o primeiro dia útil seguinte à ocorrência, exceto nos casos de morte em que o envio deve ser imediato (PWC BRASIL, 2015). 
A partir do ano de 2018, foi anunciado que o eSocial substituiria as obrigações acessórias feitas pelos empregadores, sendo algumas destas: a Declaração de Imposto de Renda Retido na Fonte (DIRF), a Guia de Informações à Previdência e Recolhimento do Fundo de Garantia por Tempo de Serviço (GFIP), a Relação Anual de Informações Sociais (RAIS) e o Cadastro Geral de Empregados e Desempregados (CAGED), facilitando o processo de fiscalização por parte dos órgãos públicos e também gerando mais controle e qualidade das informações (VELLUCCI et al. 2018).

Ressalta-se que o eSocial passou a ser obrigatório para empresas com faturamento acima de 78 milhões a partir de $1^{\circ}$ de janeiro de 2018 e, para os demais empregadores e contribuintes, passou a ser exigido de forma escalonada, ou seja, $1^{\circ}$ de julho de $2018,1^{\circ}$ de janeiro de 2019 e $1^{\text {o }}$ de janeiro de 2020 (PORTAL ESOCIAL, 2019). Entretanto, devido à complexidade, o projeto está sendo implantando em 5 fases, com os empregadores sendo divididos em quatro grupos, conforme apresenta-se no Quadro 1.

Cabe evidenciar que os grupos estão assim relacionados: empresas com faturamento anual superior a $\mathrm{R} \$ 78$ milhões (grupo 1), entidades empresariais com faturamento no ano de 2016 de até R\$ 78 milhões e que não sejam optantes pelo Simples Nacional (grupo 2), empregadores optantes pelo Simples Nacional, empregadores pessoa física (exceto doméstico), produtor rural pessoa física e entidades sem fins lucrativos (grupo 3) e órgãos públicos e organizações internacionais (grupo 4).

Quadro 1 - Cronograma de implantação do eSocial

\begin{tabular}{|c|c|c|c|l|}
\hline Grupo 1 & Grupo 2 & Grupo 3 & Grupo 4 & \multicolumn{1}{|c|}{ Fases } \\
\hline janeiro/2018 & julho/2018 & janeiro/2019 & janeiro/2020 & $\begin{array}{l}\text { Apenas informações relativas às empresas, } \\
\text { ou seja, cadastros do empregador e tabelas. }\end{array}$ \\
\hline março/2018 & outubro/2018 & abril/2019 & $\begin{array}{c}\text { Resolução } \\
\text { específica, a } \\
\text { ser publicada }\end{array}$ & $\begin{array}{l}\text { Nesta fase, empresas passam a ser obrigadas } \\
\text { a enviar informações relativas aos } \\
\text { trabalhadores e seus vínculos com as } \\
\text { empresas (eventos não periódicos), como } \\
\text { admissões, afastamentos e desligamentos. }\end{array}$ \\
\hline maio/2018 & janeiro/2019 & janeiro/2020 & $\begin{array}{c}\text { Resolução } \\
\text { específica, a } \\
\text { ser publicada }\end{array}$ & $\begin{array}{l}\text { Torna-se obrigatório o envio das folhas de } \\
\text { pagamento. }\end{array}$ \\
\hline agosto/2018 & abril/2019 & Data a definir & $\begin{array}{c}\text { Resplução } \\
\text { ser publicada a }\end{array}$ & $\begin{array}{l}\text { Substituição da GFIP para recolhimento de } \\
\text { Contribuições Previdenciárias. }\end{array}$ \\
\hline janeiro/2020 & julho/2020 & janeiro/2021 & $\begin{array}{c}\text { julho/2021 } \\
\text { Na última fase, deverão ser enviados os } \\
\text { dados de segurança e saúde do trabalhador. }\end{array}$ \\
\hline
\end{tabular}

Fonte: Portal eSocial (2019)

Percebe-se a partir das informações evidenciadas no Quadro1, que a implantação ocorreu (e está ocorrendo) de forma escalonada para todos os empregadores e contribuintes. Neste sentido, convém lembrar que para enviar informações da fase seguinte, deve ocorrer a transmissão da fase atual, servindo com uma espécie de "validação" para que os empregadores e contribuintes possam seguir adiante.

A última etapa da implantação acontece em janeiro de 2020, quando o primeiro grupo começa a enviar informações referentes a segurança e saúde do trabalhador, passando o último grupo a ser obrigado em julho de 2021. Além disto, algumas fases dos grupos 3 e 4 ainda possuem datas a ser definidas, ou seja, este cronograma ainda se encontra em construção. 


\subsection{ESTUDOS ANTERIORES SOBRE O TEMA}

No Quadro 2, são evidenciados os autores, objetivos e principais resultados observados em estudos anteriores sobre o tema.

Quadro 2 - Estudos anteriores sobre o tema

\begin{tabular}{|c|c|c|}
\hline Autores & Objetivos & Principais resultados \\
\hline $\begin{array}{c}\text { Vassoler } \\
(2015)\end{array}$ & $\begin{array}{l}\text { Identificar os impactos causados nas } \\
\text { empresas com a implantação do } \\
\text { eSocial. }\end{array}$ & $\begin{array}{l}\text { As empresas respondentes estão se preparando para se } \\
\text { adequarem a esta nova obrigação e concordam que } \\
\text { este tipo de escrituração reduzirá e agilizará o envio } \\
\text { das informações trabalhistas e previdenciárias, porém, } \\
\text { precisará haver mudança de cultura organizacional } \\
\text { para o cumprimento da legislação. }\end{array}$ \\
\hline $\begin{array}{l}\text { Reichert et } \\
\text { al. (2015) }\end{array}$ & $\begin{array}{l}\text { Identificar os desafios e benefícios para } \\
\text { os profissionais de escritórios de } \\
\text { contabilidade em um município do } \\
\text { interior do estado do RS, no que se } \\
\text { refere à implantação do eSocial nas } \\
\text { empresas. }\end{array}$ & $\begin{array}{l}\text { Os resultados demonstraram como principal desafio } \\
\text { para a implementação do eSocial é a mudança cultural } \\
\text { da empresa, sabendo que os maiores benefícios serão } \\
\text { para os empregados, e profissionais. Apesar das } \\
\text { dificuldades irá trazer benefícios nas relações de } \\
\text { trabalho e nos processos e procedimentos existentes. }\end{array}$ \\
\hline $\begin{array}{l}\text { Mann e } \\
\text { Hoffmam } \\
\text { (2015) }\end{array}$ & $\begin{array}{l}\text { Analisar o cenário de preparação para a } \\
\text { implantação do eSocial junto ao setor } \\
\text { de Recursos Humanos de empresas } \\
\text { cooperativistas } \\
\text { localizadas em Ponta Grossa- PR. }\end{array}$ & $\begin{array}{l}\text { Os resultados apontam que os respondentes estão se } \\
\text { adaptando para atender a nova obrigatoriedade, sendo } \\
\text { que os mesmos já possuem algum tipo de } \\
\text { conhecimento em relação ao eSocial. }\end{array}$ \\
\hline $\begin{array}{l}\text { Leal et al. } \\
(2016)\end{array}$ & $\begin{array}{l}\text { Analisar as perspectivas dos } \\
\text { profissionais contábeis acerca dos } \\
\text { benefícios e desafios da implementação } \\
\text { do Sistema de Escrituração Digital das } \\
\text { Obrigações Fiscais, Previdenciárias e } \\
\text { Trabalhistas (eSocial). }\end{array}$ & $\begin{array}{l}\text { Os respondentes acreditam que a implementação do } \\
\text { eSocial proporcionará diversos benefícios, como o } \\
\text { oferecimento de uma única base de dados que } \\
\text { eliminará obrigações acessórias, tornando a prestação } \\
\text { das informações relativas às obrigações do } \\
\text { empregador, mais ágil e precisa. }\end{array}$ \\
\hline $\begin{array}{l}\text { Costa, } \\
\text { Oliveira e } \\
\text { Alves } \\
(2016)\end{array}$ & $\begin{array}{l}\text { Investigar como o eSocial refletirá na } \\
\text { rotina dos profissionais da } \\
\text { Contabilidade que trabalham com o } \\
\text { departamento de pessoal das empresas } \\
\text { contratantes. }\end{array}$ & $\begin{array}{l}\text { Os resultados apontam que os respondentes possuem } \\
\text { um conhecimento significativo sobre o tema, porém } \\
\text { os mesmos ainda não se sentem preparados para as } \\
\text { mudanças que o eSocial trouxe. }\end{array}$ \\
\hline $\begin{array}{l}\text { Caon e } \\
\text { Nascimento } \\
\text { (2017) }\end{array}$ & 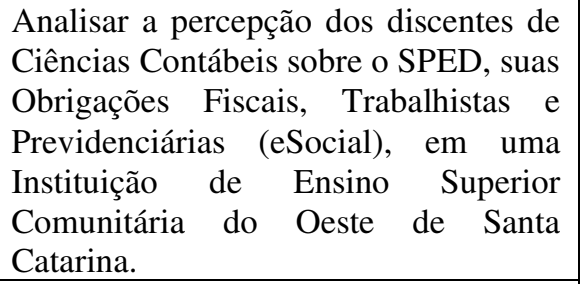 & $\begin{array}{l}\text { Os resultados apontam que os discentes apresentam } \\
\text { uma preocupação quanto à complexidade do assunto, } \\
\text { tendo em vista que as informações devem ser } \\
\text { repassadas aos órgãos governamentais de maneira } \\
\text { precisa, verídica e em tempo real. }\end{array}$ \\
\hline $\begin{array}{l}\text { Oliveira, } \\
\text { Santana e } \\
\text { Martins } \\
(2017)\end{array}$ & $\begin{array}{l}\text { Analisar as perspectivas dos } \\
\text { Contadores em relação à implantação } \\
\text { do eSocial. }\end{array}$ & $\begin{array}{l}\text { Os principais resultados apontaram que os } \\
\text { profissionais demonstraram conhecimento em relação } \\
\text { ao eSocial, no entanto, não estão preparados para esta } \\
\text { nova obrigação e pretendem investir em capacitação, } \\
\text { tecnologia da informação e consultorias. }\end{array}$ \\
\hline $\begin{array}{l}\text { Vellucci et } \\
\text { al. (2018) }\end{array}$ & $\begin{array}{l}\text { Verificar se as mudanças com o eSocial } \\
\text { necessitaram de novas rotinas no } \\
\text { departamento pessoal e o envolvimento } \\
\text { da direção com a implantação deste } \\
\text { novo projeto. }\end{array}$ & $\begin{array}{l}\text { Identificou-se que existe associação positiva } \\
\text { moderada e significante entre o envolvimento da } \\
\text { direção e a adaptabilidade ao eSocial, e quanto maior } \\
\text { for o envolvimento da direção com a implantação do } \\
\text { eSocial, mais alto será o nível de adaptabilidade da } \\
\text { empresa na implantação do eSocial. }\end{array}$ \\
\hline $\begin{array}{l}\text { Dutra, } \\
\text { Gonçalves } \\
\text { e Martins } \\
(2019)\end{array}$ & $\begin{array}{l}\text { Analisar a percepção dos acadêmicos } \\
\text { de Ciências Contábeis acerca da } \\
\text { implantação do eSocial }\end{array}$ & $\begin{array}{l}\text { Os resultados obtidos demostram que os acadêmicos } \\
\text { sentem-se pouco preparados ou desconhecem } \\
\text { completamente o eSocial. }\end{array}$ \\
\hline
\end{tabular}




\begin{tabular}{|c|l|l|}
\hline Autores & \multicolumn{1}{|c|}{ Objetivos } & \multicolumn{1}{|c|}{ Principais resultados } \\
\hline $\begin{array}{c}\text { Muller, } \\
\text { Godoy } \\
\begin{array}{c}\text { Filho e } \\
\text { Martins } \\
(2019)\end{array}\end{array}$ & $\begin{array}{l}\text { Analisar as dificuldades da implantação } \\
\text { do eSocial nas organizações contábeis. }\end{array}$ & $\begin{array}{l}\text { Observou-se a falta de qualificação para o manuseio } \\
\text { da ferramenta eSocial entre os profissionais da } \\
\text { contabilidade, e pouco entendimento sobre as } \\
\text { obrigações acessórias sobre o tema. }\end{array}$ \\
\hline $\begin{array}{c}\text { Ferreira e } \\
\text { Bonfim } \\
(2019)\end{array}$ & $\begin{array}{l}\text { Analisar os custos psicológicos para os } \\
\text { contadores na implantação de um novo } \\
\text { sistema informatizado que, no caso, foi } \\
\text { o eSocial. }\end{array}$ & $\begin{array}{l}\text { Os resultados apontaram que os profissionais estão } \\
\text { expostos ao risco de exaustão emocional, } \\
\text { despersonalização e falta de realização no trabalho. }\end{array}$ \\
\hline
\end{tabular}

Fonte: Elaborados pelos Autores (2019)

Conforme as pesquisas apresentadas anteriormente, percebe-se de maneira geral, que o eSocial se trata de um tema bastante recente e que, embora sua implantação esteja em andamento, tanto alunos, quanto profissionais e organizações contábeis ainda não se sentem capacitados para esta nova obrigação acessória. Desta forma, o tema eSocial é pertinente e atual, além de trazer elementos importantes como a integração entre fisco/empresa e demonstra a forma como a informatização contribui ou não para o avanço da contabilidade.

Cabe ressaltar que este estudo, diferentemente dos apresentados no Quadro 2, foi desenvolvido após o eSocial já ter sido implementado nas organizações contábeis que participaram da pesquisa, uma vez que a maioria dos trabalhos desenvolvidos até então tratavam da temática antes de sua obrigatoriedade.

\section{PROCEDIMENTOS METODOLÓGICOS}

Este estudo é tratado quanto à abordagem, como uma pesquisa quantitativa, em relação aos objetivos, classifica-se como uma pesquisa descritiva e no que tange aos procedimentos, como uma pesquisa de levantamento. Segundo Raupp e Beuren (2003), abordagem quantitativa é aquela que utiliza instrumentos estatísticos tanto na coleta quanto no tratamento dos dados.

Conforme Richardson (2015), a pesquisa descritiva é utilizada para analisar o papel das variáveis que influenciam ou causam o aparecimento dos fenômenos, para obter o melhor entendimento do comportamento de diversos fatores. Já Martins e Theóphilo (2009) afirmam que embora na pesquisa de levantamento possa se estudar relações de variáveis, também se estuda parte ou todos os sujeitos da pesquisa.

$\mathrm{O}$ instrumento de coleta de dados utilizado neste estudo foi um questionário validado e utilizado por Muller, Godoy Filho e Martins (2019), com 20 (vinte) questões fechadas. Neste contexto, Hair Júnior et al. (2005) observam que este tipo de instrumento se trata de um conjunto de perguntas em que as respostas são registradas pelos participantes da pesquisa.

Em relação à população e amostra, Martins e Theóphilo (2009) enfatizam que população é um conjunto de indivíduos ou objetos que apresentam características em comum definidas para o estudo e amostra é uma pequena parte da população. Sendo assim, a população deste estudo foi de 2840 escritórios de Contabilidade da Grande Florianópolis/SC, registrados no Conselho Regional de Contabilidade de Santa Catarina (CRC/SC), obtendo-se uma amostra de 61 respondentes, que representa $2,15 \%$ da população.

O questionário foi disponibilizado no período entre 17 de agosto e 06 de setembro de 2018 e foi enviado às organizações contábeis via e-mail, por intermédio do CRC/SC. Os dados foram tabulados por meio do Google Formulários ${ }^{\circledR}$ e a técnica de análise de dados utilizada foi a estatística descritiva, segundo a distribuição de frequência relativa. 


\section{ANÁLISE DOS RESULTADOS}

A análise dos resultados foi dividida em três blocos de respostas, sendo o primeiro referente às características pessoais dos respondentes, o segundo, a respeito da análise dos escritórios contábeis e por último, sobre o conhecimento das organizações contábeis em relação ao eSocial. Iniciando a análise do primeiro bloco, a Tabela 1 representa o gênero dos respondentes.

Tabela 1 - Gênero

\begin{tabular}{cc}
\hline Gênero & Frequência Relativa (\%) \\
\hline Masculino & $55,7 \%$ \\
Feminino & $44,3 \%$ \\
Total & $\mathbf{1 0 0 , 0 \%}$ \\
\hline
\end{tabular}

Fonte: Dados da Pesquisa (2019)

De acordo com a Tabela 1, 55,7\% dos respondentes são do gênero masculino, o que representa a maioria dos respondentes desta pesquisa. Entretanto, percebe-se que os representantes das organizações contábeis que participaram deste estudo estão próximos da metade em relação ao gênero. A Tabela 2 demonstra idade e escolaridade dos respondentes.

Tabela 2 - Idade e escolaridade

\begin{tabular}{cccc}
\hline Idade & Frequência Relativa (\%) & Escolaridade & Frequência Relativa (\%) \\
\hline Até 25 anos & $11,5 \%$ & Ensino médio & $0,0 \%$ \\
Entre 26 e 35 anos & $24,6 \%$ & Nível Técnico & $1,7 \%$ \\
Entre 36 e 45 anos & $42,6 \%$ & Graduado & $37,7 \%$ \\
Mais de 45 anos & $21,3 \%$ & Especialista & $50,8 \%$ \\
& & Mestrado & $9,8 \%$ \\
Total & & Doutorado & $0,0 \%$ \\
\end{tabular}

Fonte: Dados da Pesquisa (2019)

De acordo com a Tabela 2, a idade entre 36 e 45 anos predomina com 42,6\%, mostrando que este público se trata de profissionais mais maduros. Referente à escolaridade, predomina o grau de especialista, com 50,8\%, podendo-se perceber que estes profissionais continuam ligados à academia, mesmo após o término da graduação. Em seguida, a Tabela 3 expõe o tempo de trabalho e o departamento que trabalham os respondentes.

Tabela 3 - Tempo de Trabalho e departamento dos respondentes

\begin{tabular}{cccc}
\hline Tempo & Frequência Relativa (\%) & Departamento & Frequência Relativa (\%) \\
\hline Menos de 1 ano & $3,3 \%$ & Pessoal & $73,8 \%$ \\
Entre 2 e 5 anos & $24,6 \%$ & Fiscal & $8,2 \%$ \\
Entre 6 e 10 anos & $39,3 \%$ & Contábil & $14,8 \%$ \\
Entre 11 e 20 anos & $21,3 \%$ & Societário & $1,6 \%$ \\
Mais de 20 anos & $11,5 \%$ & Outros & $1,6 \%$ \\
Total & $\mathbf{1 0 0 , 0 \%}$ & Total & $\mathbf{1 0 0 , 0 \%}$ \\
\hline
\end{tabular}

Fonte: Dados da Pesquisa (2019) 
Por meio dos dados listados na Tabela 3, observa-se que a predominância do tempo de trabalho é de até 10 anos, com 67,2\%. O resultado demonstra também que o setor com mais profissionais é o pessoal, com 73,8\%, devido à demanda em larga escala de obrigações, fazendo com que os escritórios contratem pessoal qualificado para atender às declarações. Isto também é interessante para a pesquisa em si, uma vez que este é o departamento que possui contato direto com o eSocial. Em seguida, apresenta-se a análise referente ao bloco 2, que trata das organizações contábeis, conforme Tabela 4.

Tabela 4 - Localização e número de clientes da organização contábil

\begin{tabular}{cccc}
\hline Cidade & Frequência Relativa (\%) & Clientes & Frequência Relativa (\%) \\
\hline Biguaçu & $13,1 \%$ & De 01 a 10 & $0,0 \%$ \\
São José & $13,1 \%$ & De 11 a 20 & $6,7 \%$ \\
Palhoça & $8,2 \%$ & De 21 a 30 & $4,9 \%$ \\
Santo Amaro Imperatriz & $4,9 \%$ & De 31 a 40 & $19,7 \%$ \\
Florianópolis & $59,0 \%$ & De 41 a 50 & $14,8 \%$ \\
Gov. Celso Ramos & $1,7 \%$ & Acima de 50 & $45,9 \%$ \\
Total & $\mathbf{1 0 0 , 0 \%}$ & Total & $\mathbf{9 1 , 9 \%}$ \\
\hline
\end{tabular}

Fonte: Dados da Pesquisa (2019)

A Tabela 4 demonstra que $59 \%$ das organizações contábeis estão localizadas em Florianópolis, onde há maior concentração de órgãos públicos, facilitando o deslocamento diário para as obrigações. De acordo com os dados da pesquisa, observou-se que $45,9 \%$ das organizações possuem mais de 50 clientes, podendo-se afirmar que quase a maioria das empresas é de grande porte. Em seguida, é apresentado o último bloco de respostas, referente ao conhecimento das organizações contábeis em relação ao eSocial. A Tabela 5 evidencia o entendimento da organização contábil em relação ao eSocial.

Tabela 5 - Como você avalia o entendimento da organização contábil em relação ao eSocial

\begin{tabular}{cc}
\hline Entendimento & Frequência Relativa (\%) \\
\hline Não saberia avaliar & $14,8 \%$ \\
Insuficiente & $1,6 \%$ \\
Pouco Suficiente & $37,7 \%$ \\
Suficiente & $45,9 \%$ \\
Total & $\mathbf{1 0 0 , 0 \%}$ \\
\hline
\end{tabular}

Fonte: Dados da Pesquisa (2019)

Conforme a Tabela 5, observou-se que 45,9\% dos respondentes acham suficiente o conhecimento da organização em relação ao eSocial. Este resultado pode ser preocupante, uma vez que o eSocial já está em funcionamento e mais da metade das organizações respondentes não possui conhecimento suficiente em relação ao tema. Destaca-se que esta declaração envolve todos os setores da organização, corroborando com os resultados de Vassoler (2015), que concluiu que metade de sua amostra afirmou ter conhecimento suficiente da plataforma eSocial. Na Tabela 6, apresenta-se a opinião dos respondentes sobre o que mudou após a implantação do eSocial. 
Tabela 6 - O que mudou após a implantação do eSocial

\begin{tabular}{cc}
\hline Implantação do eSocial & Frequência Relativa (\%) \\
\hline Integração entre os clientes e o profissional de contabilidade & $62,3 \%$ \\
Integração dos softwares & $11,5 \%$ \\
Contratação de profissionais mais qualificados & $13,1 \%$ \\
Investimentos em segurança da informação & $11,5 \%$ \\
Nada a declarar & $1,6 \%$ \\
Total & $\mathbf{1 0 0 , 0 \%}$ \\
\hline
\end{tabular}

Fonte: Dados da Pesquisa (2019)

Percebe-se na Tabela 6, que 62,3\% dos respondentes acreditam que mudou a integração entre os clientes e o profissional de contabilidade, uma vez que esta aproximação passou a ser fundamental para a transmissão das informações dos empregados ao físco. Este achado opõese ao encontrado por Ruschel, Frezza e Utzig (2011), quando a maioria dos respondentes esperavam profissionais mais qualificados para o eSocial. Em seguida, na Tabela 7, apresentase o impacto do eSocial na organização contábil.

Tabela 7 - Como você considera o impacto do eSocial em sua organização contábil

\begin{tabular}{cc}
\hline Impacto & Frequência Relativa (\%) \\
\hline $\begin{array}{c}\text { Impacto positivo, pois desta maneira os empresários tiveram que se } \\
\text { adequar as normas e trabalhar de maneira mais correta }\end{array}$ \\
$\begin{array}{cc}\text { Impacto positivo, pois as exigências dos profissionais contábeis } \\
\text { aumentaram, o que exigiu mais capacitação. }\end{array}$ \\
Aumentou o nível de responsabilidade & $49,2 \%$ \\
Acarretou muita dificuldade & $18,0 \%$ \\
Total & $14,0 \%$ \\
\hline
\end{tabular}

Fonte: Dados da Pesquisa (2019)

Corroborando com Barp, Fortes e Sonaglio (2014), 49,2\% dos respondentes afirmaram que houve um impacto positivo, pois, as exigências dos profissionais da área aumentaram, desta maneira, exigindo mais dedicação, capacitação e qualificação profissional. Neste contexto, acredita-se que a integração entre cliente e profissional contábil (evidenciado na Tabela 6), complementa a percepção das organizações quanto ao impacto positivo do eSocial. Na Tabela 8, aponta-se a preparação dos empregadores e colaboradores em relação às mudanças e procedimentos do eSocial.

Tabela 8 - Os empregadores e colaboradores estão preparados para as mudanças de procedimentos que o eSocial exige

\begin{tabular}{cc}
\hline Preparação dos envolvidos & Frequência Relativa (\%) \\
\hline Discordo totalmente & $13,1 \%$ \\
Discordo & $31,1 \%$ \\
Nem concordo nem discordo & $21,3 \%$ \\
Concordo & $19,7 \%$ \\
Concordo totalmente & $14,8 \%$ \\
Total & $\mathbf{1 0 0 , 0 \%}$ \\
\hline
\end{tabular}

Fonte: Dados da Pesquisa (2019) 
Percebe-se que $31,10 \%$ dos respondentes discordam que estão preparados para utilizar o eSocial, mostrando um resultado preocupante. Estes profissionais já deveriam estar adequados para esta plataforma, pois a mesma já se encontra em funcionamento. A partir deste achado, percebe-se o quanto é fundamental a aproximação entre empresa e profissional contábil para que este possa auxiliar estas organizações com as mudanças de procedimentos que o eSocial trouxe. Este resultado corrobora com Abrantes (2014). Na Tabela 9, verifica-se a redução da informalidade na prestação das informações trabalhistas e previdenciárias.

Tabela 9 - A implantação do eSocial reduziu informalidade na prestação das informações trabalhistas e previdenciárias

\begin{tabular}{cc}
\hline Implantação & Frequência Relativa (\%) \\
\hline Discordo totalmente & $21,3 \%$ \\
Discordo & $9,8 \%$ \\
Nem concordo nem discordo & $24,6 \%$ \\
Concordo & $24,6 \%$ \\
Concordo totalmente & $19,7 \%$ \\
Total & $\mathbf{1 0 0 , 0 \%}$ \\
\hline
\end{tabular}

Fonte: Dados da Pesquisa (2019)

De acordo com a Tabela 9, 24,6\% dos respondentes concordam que houve redução, e outros $24,6 \%$ nem concordam e nem discordam. Acredita-se que pelo motivo de as empresas e empregados não estarem totalmente familiarizados com os novos procedimentos trazidos pelo eSocial, tenha ocasionado uma divisão entre as respostas. Este resultado corrobora parcialmente com Vassoler (2015), quando seus respondentes concordam que houve redução da informalidade na prestação das informações. A Tabela 10 apresenta o conhecimento sobre o tema eSocial pela primeira vez.

Tabela 10 - Quando você teve conhecimento sobre o tema "eSocial" pela primeira vez

\begin{tabular}{cc}
\hline Conhecimento & Frequência Relativa (\%) \\
\hline Não sei do que se trata & $0,0 \%$ \\
Há menos de um mês & $0,0 \%$ \\
De 3 a 6 meses atrás & $1,6 \%$ \\
De 6 meses a 1 ano & $4,9 \%$ \\
De 1 ano a 2 anos & $6,6 \%$ \\
Mais de 2 anos & $86,9 \%$ \\
Total & $\mathbf{1 0 0 , 0 \%}$ \\
\hline
\end{tabular}

Fonte: Dados da Pesquisa (2019)

De acordo com a Tabela 10, a grande maioria dos respondentes $(86,9 \%)$ tomaram conhecimento do eSocial há mais de 2 anos, evidenciando que as organizações contábeis não tiveram que se adequar a esta obrigação "da noite para o dia". Este resultado corrobora com a pesquisa de Mann e Hoffmam (2015). A Tabela 11 apresenta a quantidade de eventos e a carga horária dos eventos sobre o eSocial que a organização contábil já participou. 
Tabela 11 - Eventos (palestras, cursos, treinamentos, seminários) e carga horária total somando todos os eventos que a organização contábil já participou sobre o eSocial

\begin{tabular}{cccc}
\hline Eventos & Frequência Relativa (\%) & Carga Horária Total & Frequência Relativa (\%) \\
\hline Nenhum & $14,8 \%$ & 0 horas & $13,1 \%$ \\
Apenas 1 & $14,8 \%$ & 1 a 2 horas & $3,2 \%$ \\
De 2 a 5 & $32,8 \%$ & 3 a 10 horas & $19,7 \%$ \\
De 6 a 10 & $21,2 \%$ & 11 a 20 horas & $26,2 \%$ \\
Mais de 10 & $16,4 \%$ & 21 a 50 horas & $23,0 \%$ \\
& & Mais de 50 horas & $14,8 \%$ \\
Total & $\mathbf{1 0 0 , 0 \%}$ & Total & $\mathbf{1 0 0 , 0 \%}$ \\
\hline
\end{tabular}

Fonte: Dados da Pesquisa (2019)

Percebe-se na Tabela 11 , que $62,4 \%$ dos respondentes participaram de no máximo 5 eventos. Ressalta-se que este número é muito baixo para ter capacitação adequada em relação ao eSocial, visto que de acordo com a Tabela 10, muitos já tiveram conhecimento do eSocial há mais de 2 anos, logo, poderiam ter participado de mais eventos. Já em relação à carga horária, $62,3 \%$ fizeram até 20 horas de curso, que também é considerado como um número muito baixo. Isto demonstra que um dos motivos para as organizações contábeis não estarem preparadas, é a falta de conhecimento. Os dados expostos na Tabela 11 corroboram com a pesquisa de Oliveira, Santana e Martins (2017). A Tabela 12 evidencia qual entidade mais promoveu capacitações, de acordo com os respondentes.

Tabela 12 - Em geral, quais foram as entidades que promoveram os eventos no qual a organização contábil participou sobre o eSocial

\begin{tabular}{cc}
\hline Locais & Frequência Relativa (\%) \\
\hline Nenhuma & $13,2 \%$ \\
Receita Federal do Brasil - RFB & $0,0 \%$ \\
Ministério do Trabalho e Emprego - MTE & $0,0 \%$ \\
Conselho Regional de Contabilidade - CRC & $77,0 \%$ \\
Associação Comercial & $0,0 \%$ \\
Empresas produtoras de software & $9,8 \%$ \\
Total & $\mathbf{1 0 0 , 0 \%}$ \\
\hline
\end{tabular}

Fonte: Dados da Pesquisa (2019)

De acordo com a Tabela 12, destacou-se o CRC, com 77\%. Este órgão possui muitas atividades de capacitação e atualização dos profissionais contábeis, tais como palestras, cursos e programas de educação continuada, corroborando com a pesquisa de Muller, Godoy Filho e Martins (2019). A Tabela 13 identifica a opinião dos respondentes em relação ao prazo de implantação do eSocial.

Tabela 13 - Na sua opinião, o prazo de implantação do eSocial na sua empresa

\begin{tabular}{cc}
\hline Prazo & Frequência Relativa (\%) \\
\hline Não sei responder & $13,1 \%$ \\
Pouco tempo para se adequar & $49,2 \%$ \\
Tempo suficiente para se adequar & $27,9 \%$ \\
Mais do que suficiente & $9,8 \%$ \\
Total & $\mathbf{1 0 0 , 0 \%}$ \\
\hline
\end{tabular}

Fonte: Dados da Pesquisa (2019) 
Percebe-se na Tabela 13, que 49,2\% dos respondentes alegaram que tiveram pouco tempo para se adequar à implantação do eSocial, opondo-se à pesquisa de Muller, Godoy Filho e Martins (2019), quando 44,3\% dos participantes do estudo alegaram ter tempo suficiente para implantação do eSocial. Cabe salientar que a grande maioria das empresas participantes deste estudo afirmou conhecer o tema há mais de 2 anos, entretanto, ainda enfatizam que tiveram pouco tempo para se adequar à nova obrigação. A Tabela 14 apresenta quais as maiores que dificuldades que as organizações contábeis encontraram ao implantar o eSocial.

Tabela 14 - Maiores dificuldades que a organização contábil encontrou para adequação ao eSocial

\begin{tabular}{cc}
\hline Dificuldades & Frequência Relativa (\%) \\
\hline Nenhuma & $0,0 \%$ \\
Cumprir a legislação em vigor & $3,3 \%$ \\
Conscientizar os gestores e empresários da importância desta nova declaração & $36,1 \%$ \\
Cumprir os prazos & $52,5 \%$ \\
Entender o leiaute dos arquivos & $4,8 \%$ \\
Estabelecer uma boa comunicação entre os departamentos das empresas & $3,3 \%$ \\
Total & $\mathbf{1 0 0 , 0 \%}$ \\
\hline
\end{tabular}

Fonte: Dados da Pesquisa (2019)

Evidencia-se na Tabela 14, que 52,5\% dos respondentes acreditam que a maior dificuldade foi cumprir os prazos desta nova declaração, uma vez que acharam pouco tempo para se adequar ao eSocial. Este achado opõe-se aos resultados de Costa, Oliveira e Alves (2016), quando a maioria dos respondentes apontou que a maior dificuldade foi a conscientização e comprometimento dos empresários. A Tabela 15 mostra, de acordo com a visão dos respondentes, se várias obrigações acessórias foram eliminadas com a implantação do eSocial.

Tabela 15 - O eSocial possibilitou a eliminação de diversas obrigações acessórias, como: GFIP, CAGED, RAIS, DIRF, entre outras.

\begin{tabular}{cc}
\hline Eliminação de declaração acessória & Frequência Relativa (\%) \\
\hline Discordo totalmente & $57,4 \%$ \\
Discordo & $8,2 \%$ \\
Nem concordo nem discordo & $23,0 \%$ \\
Concordo & $9,8 \%$ \\
Concordo totalmente & $1,6 \%$ \\
Total & $\mathbf{1 0 0 , 0 \%}$ \\
\hline
\end{tabular}

Fonte: Dados da Pesquisa (2019)

Percebe-se na Tabela 15, que 57,4\% dos respondentes discordam totalmente que o eSocial possibilitou a eliminação destas obrigações acessórias, uma vez que mesmo já estando obrigadas à transmissão do eSocial, as empresas continuam com a necessidade de transmissão das "antigas" declarações. Isto se opõe aos resultados encontrados por Leal et al. (2016), quando afirmam que $67 \%$ dos participantes de seu estudo concordam que houve eliminação destas obrigações acessórias. A Tabela 16 mostra qual o conhecimento da organização contábil em relação às penalidades do eSocial. 
Tabela 16 - Qual o conhecimento da organização contábil em relação às penalidades do eSocial

\begin{tabular}{cc}
\hline Conhecimento sobre as penalidades & Frequência Relativa (\%) \\
\hline Nenhum conhecimento & $13,1 \%$ \\
Baixo & $6,6 \%$ \\
Médio & $26,2 \%$ \\
Alto & $41,0 \%$ \\
Excelente & $13,1 \%$ \\
Total & $\mathbf{1 0 0 , 0 \%}$ \\
\hline
\end{tabular}

Fonte: Dados da Pesquisa (2019)

Evidencia-se na Tabela 16, que 54,1\% dos respondentes tem um grau de conhecimento alto ou excelente em relação a estas penalidades. Este resultado aponta que, embora as organizações considerem pequeno o tempo para adequação ao eSocial, estão cientes das penalidades que estão sujeitas caso não cumpram com a obrigação. Este resultado é distinto ao encontrado na pesquisa de Muller, Godoy Filho e Martins (2019), quando evidenciaram que a maior frequência encontrada foi que $36,4 \%$ de seus respondentes possuíam médio conhecimento destas penalidades. Isto comprova que as organizações buscaram novos conhecimentos em relação às penalidades.

\section{CONSIDERAÇÕES FINAIS}

Este artigo teve como objetivo analisar os desafios de organizações contábeis acerca do eSocial após sua implementação. Evidencia-se na pesquisa que os maiores desafios foram em relação ao cumprimento de prazos e na conscientização dos gestores e empresários da importância desta nova plataforma.

De acordo com a análise da pesquisa, as organizações contábeis acreditam que a implantação do eSocial teve um impacto positivo, pois além de melhorar a integração entre os clientes e os profissionais contábeis, também fez com que os empregadores se adequassem melhor as normas e trabalhassem de maneira correta, embora reconheçam que os empregadores e colaboradores ainda não estão preparados com tal mudança.

Muitas organizações avaliam ter entendimento suficiente do eSocial, porém, a quantidade e carga horária das capacitações obtidas, foram muito baixas, não sendo adequadas para um bom entendimento do assunto. $\mathrm{O}$ ideal é que estas organizações procurem fazer mais capacitações ou até mesmo os empregadores, para que possam aumentar o nível de conhecimento e trabalhar corretamente com o sistema, evitando problemas futuros pelo uso inadequado da ferramenta.

Concluiu-se também, na percepção dos autores, que o eSocial só tende a beneficiar todas as partes envolvidas, sendo o empregador, o empregado, as organizações contábeis, e o próprio fisco, pois trouxe maior transparência e padronização nos processos, integração dos sistemas dos órgãos e instituições, como: RFB, MTPS, INSS e CEF, e evitando o retrabalho e burocratização de vários processos.

Desta forma, percebe-se que o eSocial trouxe importantes elementos de integração entre o fisco e as empresas, aproveitando-se do crescente avanço da informática no dia a dia das organizações. Além disto, observa-se que a obrigatoriedade desta obrigação proporcionou uma maior aproximação entre organizações contábeis e clientes, devido às mudanças de procedimentos que ocorreram para adequação à esta nova realidade empresarial. Assim, tornase necessário que as entidades estejam preparadas para as mudanças (que são cada vez mais frequentes) e aproveitem os pontos que contribuam para seu desenvolvimento. 
Ressalta-se que o presente estudo contribuiu para analisar o conhecimento das organizações contábeis após a implantação do eSocial de forma que, ao se conhecer os maiores desafios em sua implementação, pode proporcionar resultados positivos em relação ao grau de suficiência do conhecimento das organizações sobre a plataforma. Pode-se aprender com este artigo que, além dos profissionais se considerarem suficientemente preparados, deve-se constantemente frequentar novas palestras e eventos para atualizar e agregar conhecimento.

Desta forma, ressalta-se que a pergunta de pesquisa foi respondida, os objetivos foram atingidos, e a metodologia utilizada foi adequada. Como limitações deste estudo, enfatiza-se a amostra como fator limitante, com um número muito baixo de respondentes, e, além disto, a dificuldade de obter retorno das organizações contábeis quanto às respostas dos questionários.

Sugere-se para trabalhos futuros, replicar esta pesquisa com uma amostra maior, com um público mais específico de Recursos Humanos e Departamento Pessoal de todo o estado de Santa Catarina ou em outros estados do país. Também recomenda-se utilizar como objeto de pesquisa estudantes de Ciências Contábeis. Propõe-se ainda, uma pesquisa qualitativa, para compreender em maior profundidade como se deu a implantação do eSocial nas organizações.

\section{REFERÊNCIAS}

ABRANTES, D. S. EFD-Social: As empresas atacadistas de alimentos de Campina Grande estão realmente preparadas para essa nova obrigatoriedade?. 2014. 28 f. Trabalho de Conclusão de Curso (Graduação em Ciências Contábeis) - Universidade Estadual do Paraíba, Campina Grande, 2014.

AZEVEDO, O. R.; MARIANO, P. A. SPED: Sistema Público de Escrituração Digital. 7 ed. São Paulo: IOB Sage, 2011.

BARP, A. D.; FORTES, M. M. S.; SONAGLIO, D. Implementação do Sistema Público de Escrituração Digital: Mudanças na percepção cotidiana dos profissionais de contabilidade. In: CONGRESSO INTERNACIONAL DE GESTÃO DA TECNOLOGIA E SISTEMAS DE INFORMAÇÃO, 11, 2014, São Paulo/SP. Anais[...]. São Paulo: USP, 2014.

BARP, A. D.; VIEIRA, A. T.; MARTINS, Z. B. Sistema Público de escrituração digital SPED: Adaptações para uso e implementação por profissionais de contabilidade. In: CONGRESSO INTERNACIONAL DE GESTÃO DA TECNOLOGIA E SISTEMAS DE INFORMAÇÃO, 11, 2014, São Paulo/SP. Anais[...]. São Paulo: USP, 2014.

CAON, A.; NASCIMENTO, S. Percepção dos discentes de Ciências Contábeis sobre o Sistema de Escrituração Digital das Obrigações Fiscais, Trabalhistas e Previdenciária (eSocial). Revista de Contabilidade do Mestrado em Ciências Contábeis da UERJ, v. 22, n. 1, p. 3-27, 2017.

COSTA, L. V.; OLIVEIRA, C. D.; ALVES, R. A. eSocial: Estudos sobre seus reflexos na rotina de profissionais da contabilidade. In: CONGRESSO BRASILEIRO DE CONTABILIDADE, 20, 2016, Fortaleza/CE. Anais[...]. Brasília: Conselho Federal de Contabilidade, 2016.

COSTA, S. L. et al. Implantação do eSocial nas entidades públicas pela perspectiva de contadores públicos paraibanos. Caderno Profissional de Administração da UNIMEP, v. 8, n. 1, p. 91-107, 2018. 
DUARTE, R. D. Big Brother Fiscal IV: Manual de sobrevivência do empreendedor no mundo pós-SPED. Belo Horizonte: ideas@work, 2011.

DUTRA, F. S.; GONÇALVES, M. C.; MARTINS, Z. B. A percepção dos acadêmicos de Ciências Contábeis acerca da implantação do eSocial. Revista Brasileira de Contabilidade, v. 1, n. 238, p. 38-49, 2019.

FERREIRA, D. M.; BONFIM, M. P. Custos psicológicos na implantação do eSocial: Um estudo com profissionais contábeis. Revista de Administração e Contabilidade da FAT, v. 11, n. 2, p. 19-35, 2019.

FILIPIN, R. et al. Impactos e Benefícios da Implantação do EFD Social para os Profissionais de Escritórios de Contabilidade. Revista Gestão \& Planejamento, v. 17, n. 2, p. 367-382, 2016.

GONÇALVES, A. et al. Factors that Influence the Adoption and Implementation of Public Digital Accounting According to the Evaluation by Managers of Brazilian Companies. Journal of Information Systems and Technology Management, v. 13, n. 2, p. 193-218, 2016.

HAIR JÚNIOR, J. F. et al. Fundamentos de Métodos de Pesquisa em Administração. Porto Alegre: Bookman, 2005.

LEAL, J. M. R. et al. Implementação do eSocial: benefícios e desafios sob as perspectivas dos profissionais contábeis da Paraíba. Revista Gestão e Organizações, v. 1, n. 1, p. 124-142, 2016.

MANN, H. S. K.; HOFFMAM, R. C. A implantação do eSocial sob a ótica dos profissionais de RH das cooperativas agropecuárias de Ponta Grossa - PR. In: CONGRESSO INTERNACIONAL DE ADMINISTRAÇÃO, 25, 2015, Ponta Grossa/PR. Anais[...]. Ponta Grossa: UEPG, 2015.

MARTINS, G. A.; THEÓPHILO, C. R. Metodologia da investigação científica para Ciências Sociais Aplicadas. 2 ed. São Paulo: Atlas 2009.

MULLER, A. C.; GODOY FILHO, A. R.; MARTINS, Z. B. Dificuldades para implantação do eSocial nas organizações contábeis. Research, Society and Development, v. 8, n. 2, p. 1$24,2019$.

OLIVEIRA, L. S.; SANTANA, T. P.; MARTINS, Z. B. Perspectivas dos Contadores em relação à implantação do eSocial. Revista Mineira de Contabilidade, v. 18, n. 2, p. 41-53, 2017.

ORIGUELA, L. A. Os Principais Impactos do SPED na Profissão Contábil: Uma Análise da Percepção dos Profissionais de Contabilidade. Caderno Profissional de Administração da UNIMEP, v. 7, n. 1, p. 45-62, 2017.

PORTAL ESOCIAL. Cronograma do eSocial. 2019. Disponível em: http://portal.esocial.gov.br/noticias/confira-o-novo-calendario-de-obrigatoriedade-do-esocial. Acesso em: 29 jan. 2020. 
PWC BRASIL. A evolução das empresas rumo ao eSocial. 2015. Disponível em: https://www.pwc.com.br/pt/publicacoes/servicos/assets/consultoria-negocios/pesquisaesocial-2015e.pdf. Acesso em: 14 out. 2018.

RAUPP, F. M.; BEUREN, I. M. Metodologia da pesquisa aplicável às Ciências Sociais: Como elaborar trabalhos monográficos em contabilidade: teoria e prática. São Paulo: Atlas, 2003.

REICHERT, N. S. et al. Implantação do EFD Social para os profissionais de escritórios de contabilidade. 2015. 17 f. Trabalho de Conclusão de Curso (Graduação em Ciências Contábeis) - Universidade Regional Unijuí, Unijuí, 2015.

RICHARDSON, R. J. Pesquisa Social: Métodos e técnicas. 3 ed. São Paulo: Atlas, 2015.

RUSCHEL, M. E.; FREZZA, R.; UTZIG, M. J. S. O impacto do SPED na contabilidade desafios e perspectivas do profissional contábil. Revista Catarinense da Ciência Contábil, v. 10, n. 29, p. 9-26, 2011.

VELLUCCI, R. G. et al. Os desafios da implantação do eSocial. Revista da Micro e Pequena Empresa, v. 12, n. 1, p. 67-81, 2018.

VASSOLER, H. D. O Sistema de Escrituração Fiscal Digital das Obrigações Fiscais Previdenciárias e Trabalhistas - eSocial. 2015. 49 f. Trabalho de conclusão de curso (Graduação em Ciências Contábeis) - Universidade do Extremo Sul Catarinense, Criciúma, 2015. 